\title{
Identification of Adulteration of Olive Oil with Other Edible Oils by LED-induced Fluorescence and Multivariate Calibration
}

\author{
Marilena Meira ${ }^{1}$, Cristina M. Quintella ${ }^{2}$, Erika M. de O. Ribeiro ${ }^{2}$, Mariana A. Santos ${ }^{3}$, Saionara Luna ${ }^{2}, \&$ \\ Alexandre Lopes Del Cid ${ }^{2}$ \\ ${ }^{1}$ Instituto Federal de Educação, Ciência e Tecnologia da Bahia - IFBA, Campus de Simões Filho, BA, Brazil. \\ CEP: 43.700-000. \\ ${ }^{2}$ Instituto de Química, Universidade Federal da Bahia, Campus de Ondina, Salvador, BA, Brazil. CEP: \\ 40.170-290. \\ ${ }^{3}$ Instituto Federal de Educação, Ciência e Tecnologia da Bahia- IFBA, Campus Salvador, BA, Brazil, CEP: \\ 40110-150. \\ Correspondence: Marilena Meira, Instituto Federal de Educação, Ciência e Tecnologia da Bahia - IFBA, \\ Campus de Simões Filho, BA, Brazil, CEP: 43.700-000. E-mail: marilenameira@ gmail.com
}

Received: July 28, 2014 Accepted: August 18, 2014 Online Published: October 24, 2014

doi:10.5539/ijc.v6n4p31 URL: http://dx.doi.org/10.5539/ijc.v6n4p31

\begin{abstract}
The most common adulterants found in extra-virgin olive oil are refined olive oil and other vegetable oils, such as sunflower, soybean, corn, and canola. In addition to constituting economic fraud, adulteration can cause serious damage to the health of the consumer. This study focuses on the detection and quantification of the adulteration of extra-virgin olive oil with edible oils, using spectrofluorimetry and chemometrics. The data were analyzed by Principal Components Analysis (PCA) and Partial Least Squares (PLS) analysis. Through PCA, it was possible to separate the samples into two distinct areas, olive oil and other edible oils, based on their chemical composition. The PLS model, built with the spectra of mixtures of soybean oil in extra-virgin olive oil, exhibited an $\mathrm{R}^{2}$ of 0.99412 and low RMSEP (Root Mean Square Error of Prediction) (3.59), RMSEC (Root Mean Square Error of Calibration) (2.32) and bias (4.77. 10 $0^{-7}$ ) values. Thus, the PLS model was considered exact for calibration and prediction.
\end{abstract}

Keywords: virgin and extra-virgin olive oil, adulterations, fluorescence, PCA, PLS.

\section{Introduction}

Olive oil is a type of oil produced from the fruit of the olive tree. The name "olive oil" can only be applied to pure oil obtained from olives, not to mixtures composed of this oil and other oils such as soybean or corn, which are generically known as oil compounds. The use of olive oil dates back millennia, but its exact origin is unknown. Olive cultivation has occurred for more than 5000 years. The Phoenicians, Syrians, and Armenians were the first people to consume olive oil, and it was introduced to Europe and the West by the Greeks and Romans. For a long time, the consumption of olive oil was restricted to the Mediterranean, but in the sixteenth century, the Spaniards reported its use in the regions of South America, Central America, and the United States. There are records detailing the use of olive oil 5000 years ago by Mesopotamian peoples, who anointed their bodies with oil to protect themselves from extreme cold. In the Roman Empire, olive oil was used to soften skin and dry hair. In Greece, athletes used the oil to improve their performance. In the sixteenth century, olive oil was the basis for many drugs (Oliva, 2011).

The importance of olive oil has grown over the years due to its multiple uses in food, medicine, hygiene, and cosmetics. Many of the benefits of olive oil vaunted by popular wisdom have been proven by several scientific studies. The major differentiation of olive oil from other edible oils is associated with the higher content of monounsaturated fatty acids such as oleic acid, and reduced content of saturated fatty acids, which assist in the control of cholesterol in the blood, helping to reduce "bad" cholesterol (LDL) while maintaining an appropriate level of "good" cholesterol (HDL) (Huang \& Sumpio, 2008; Van Tol et al., 1999). Olive oil also distinguishes 
itself by its high level of the triterpene squalene, which promotes the excretion of toxins and has anticarcinogenic effects. The presence of steroids such as B-sitosterol helps to lower cholesterol and to aid in the prevention and treatment of prostate cancer, colon cancer and breast cancer (Menendez et al., 2006). Olive oil also has phenolic compounds, vitamin $\mathrm{E}$ and $\beta$-carotene, which are powerful antioxidants that react with free radicals, thus inhibiting platelet aggregation and preventing LDL oxidation (Aguilera et al., 2004). Due to its composition, olive oil provides a major contribution to the prevention and treatment of many diseases such as atherosclerosis (Acín et al., 2005), thrombosis (De La Cruz et al., 2000), diabetes mellitus (De La Cruz et al., 2010), biliary disease, cataracts and eye diseases (Aparicio-Ruiz, Mínguez-Mosquera \& Gandul-Rojas, 2011), depression (Logan, 2005), bone mineralization (Coxam, Puel \& Davicco, 2010), hypertension (Perona et al., 2004), and cancer (breast, prostate, digestive tract) (Fabiani \& Morozzi, 2010; Fernández-Arroyo et al., 2012; Flynn \& Mega, 2010; Menendez et al., 2006). In addition, regular consumption of olive oil has a protective effect against free radicals in the skin, and increases life expectancy because it strengthens the immune system and protects against memory loss due to age (Viola \& Viola, 2009; Baccouri et al., 2008).

According to the Brazilian Association of Producers, Importers and Traders of Olive Oil (Oliva, 2011), olive oil is graded based on organoleptic characteristics (taste and aroma), chemistry (acidity and other chemical data) and the following three types of extraction:

- Extra-virgin olive oil is produced by a mechanical pressing extraction process. It has flawless flavor and taste and less than $1 \%$ acidity.

- Olive oil is also produced by a mechanical pressing extraction process. It has outstanding flavor and aroma with acidity below $2 \%$.

- Pure olive oil is formed by blending refined olive oil and virgin olive oil and has less than $1.5 \%$ acidity.

Olive pomace is one of the main sub-products of the processing of olives after pressing to extract the oil. The olive residue has a low oil content and low oxidative stability due to a moisture content that accelerates the hydrolysis of triacylglycerol. Generally, olive oil from the pomace is extracted with solvent and subjected to the refining process, including neutralization, bleaching and deodorizing.

Due to its low price, sometimes refined oil is used to adulterate olive oil of better quality, such as pure, virgin and extra-virgin olive oil. Similarly, due to lower market prices, edible oils such as soybean, corn, canola, cotton, sunflower, peanut and almond are likely to be used as illicit adulterants of olive oil. Therefore, a rapid method to detect adulteration is important for purposes of quality control and labeling olive oils of better quality (Guimet, Ferré \& Boqué, 2005).

Several analytical methodologies have been developed in recent years to ensure the authenticity of olive oil. These methods include chromatographic techniques (Bosque-Sendra et al., 2012; Baccouri et al., 2008) and spectroscopic techniques, such as mass spectrometry (Calvano et al., 2012), Nuclear Magnetic Resonance (NMR) (Fragaki et al., 2005), near-infrared spectroscopy (Mignani et al., 2011), Raman spectroscopy (Dong et al., 2012), chemiluminescence (Papadopoulos et al., 2002), fluorescence spectroscopy (Sikorska, Khmelinskii \& Sikorski, 2012), and synchronous fluorescence (Poulli, Mousdis \& Georgiou, 2007).

This study focuses on the detection and quantification of adulteration of extra-virgin olive oil with edible oils, using a combination of LED-induced spectrofluorimetry and chemometrics.

\section{Materials and Methods}

\subsection{Samples}

Oils were purchased from a supplier located in Salvador in Bahia, Brazil.We used 56 samples of oils, 10 being of extra-virgin olive oil, 10 of soybean, 13 of corn, 10 of canola and 13 of sunflower.

\section{Mixtures of extra-virgin olive oil with adulterants}

Mixtures of extra-virgin olive oil with soybean oil as an adulterant were analyzed at $0 \%, 5 \%, 10 \%, 15 \%, 30 \%$, $35 \%, 45 \%, 50 \%, 55 \%, 60 \%, 65 \%, 70 \%, 75 \%, 85 \%, 90 \%$ and $100 \%$.

\subsection{Principal Component Analysis}

A Perkin Elmer-LS55 spectrofluorometer (U.S.A.) and $1 \mathrm{~cm}$ quartz cuvettes were used. The fluorescent emission spectra of the samples were obtained at $230-800 \mathrm{~nm}$ in intervals of $0.5 \mathrm{~nm}$, while the sample was excited at wavelengths from 200-775 nm with increments of $25 \mathrm{~nm}$. A total of 24 excitation wavelengths and 1142 emission wavelengths were obtained for each sample. The measurements were made with a slit of $2.5 \mathrm{~nm}$ and a scan speed of $1200 \mathrm{~nm} / \mathrm{min}$. The spectrofluorimetric maps were generated with Origin $8.0^{\circledR}$. 
For PCA of pure samples, the spectra were initially organized in a cube with the following dimensions: 5 samples $\mathrm{x} 1142$ emission wavelengths $\mathrm{x} 24$ excitation wavelengths. The cube was transformed by the command unfoldm in MatLab6. ${ }^{\circledR}$ to generate a general matrix with dimensions of 5 x 27408. This matrix was mean centered and then subjected to multivariate analysis with MatLab6.1 ${ }^{\circledR}$.

\subsection{PLS Analysis}

For the PLS analysis, mixtures of extra-virgin olive oil with soybean oil were assessed using a Quimis LED spectrofluorometer model Q-798FIL (Brazil) equipped with a violet LED centered at $400 \mathrm{~nm}$, and the emission was captured in the range of 400-1018 nm. The amount of soybean oil added to the extra-virgin olive oil is described in Table 1.

Table 1. Mixtures of extra-virgin olive oil and soybean oil in the range of $0-100 \%$.

\begin{tabular}{ccc}
\hline Sample number & \% Soybean oil & \% Extra-virgin olive oil \\
\hline 1 & 0 & 100 \\
2 & 5 & 95 \\
3 & 10 & 90 \\
4 & 15 & 85 \\
5 & 30 & 70 \\
6 & 35 & 65 \\
7 & 45 & 55 \\
8 & 50 & 50 \\
9 & 55 & 45 \\
10 & 60 & 40 \\
11 & 65 & 35 \\
12 & 70 & 30 \\
13 & 75 & 25 \\
14 & 85 & 15 \\
15 & 90 & 10 \\
16 & 100 & 0 \\
\hline
\end{tabular}

\section{Results and Discussion}

\subsection{Fluorescence Maps}

Comparing the fluorescence maps of extra-virgin olive oil (Figure 1) with other oils (Figure 2) shows that the extra-virgin olive oil has an emission-excitation band concentrated in three distinct regions, with peaks at 375 $\mathrm{nm}$ excitation and $520 \mathrm{~nm}$ emission, $325 \mathrm{~nm}$ excitation and $400 \mathrm{~nm}$ emission, and $375 \mathrm{~nm}$ excitation and $430 \mathrm{~nm}$ emission. The other oils have concentrated bands at approximately $350 \mathrm{~nm}$ excitation and $450 \mathrm{~nm}$ emission.

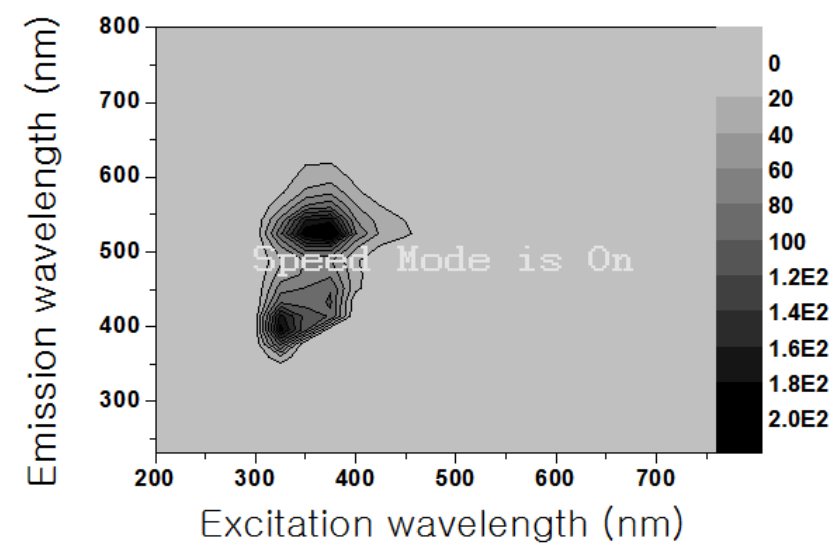

Figure 1. Contour map of the fluorescence spectra of extra-virgin olive oil. 

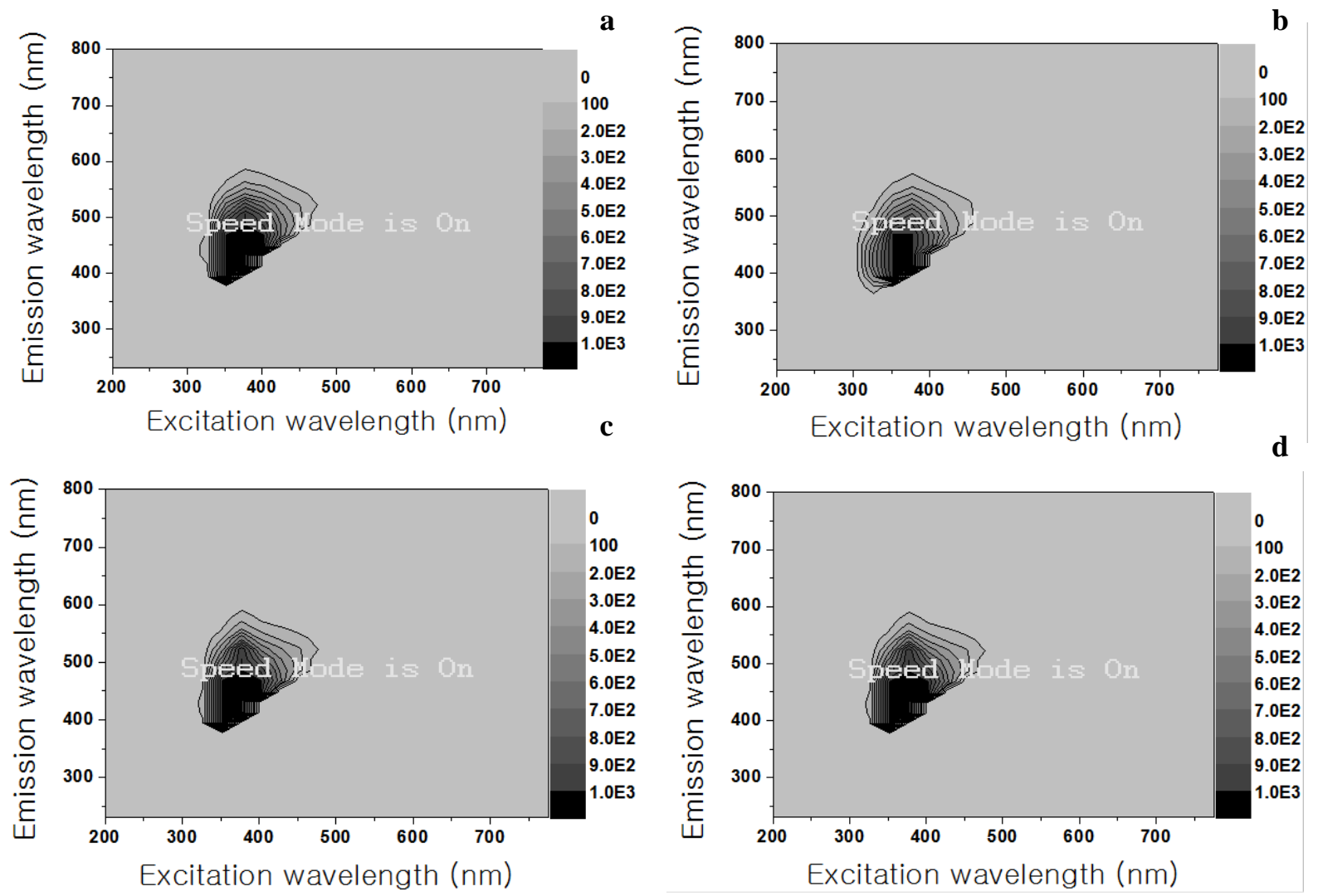

Figure 2. Contour maps of the fluorescence spectra of canola (a), sunflower (b), corn (c) and soybean (d).

\subsection{PCA of Pure Samples}

Through PCA, we found that only two principal components (PC) explained $89.87 \%$ of the variance of the data, $79.33 \%$ by PC1 and $10.54 \%$ by PC2. PC1 separated the samples by their chemical composition into two distinct areas, olive oil and other edible oils (Figure 3). The sample of extra-virgin olive oil has negative scores, and the samples of vegetable oils have positive scores.

The different fatty acid compositions of olive oil and other oils (ANVISA, 1999; Lee et al., 1998; Kim et al., 2010) may explain the differences found among the excitation-emission matrices shown by PCA. Extra-virgin olive oil is rich in oleic acid (55-83\%), which is monounsaturated, while corn, soybean and sunflower oils predominantly contain polyunsaturated fatty acids. Sunflower oil has the highest content of linoleic acid (55-75\%), which has two double bonds. Canola oil has an oleic acid composition similar to that of olive oil. However, canola oil has 5-13\% linolenic acid (three double bonds), while olive oil has less than $0.9 \%$. In addition, because extra-virgin olive oil is pressed, it retains higher levels of other fluorophores such as tocopherols, $\beta$-carotene and phenolic compounds that are refined out of other oils.

The spectra that most influenced the separation of extra-virgin olive oil (PC1 negative) from other vegetable oils ( $\mathrm{PC} 1$ positive) were the peaks at $325 \mathrm{~nm}$ excitation and 382, $523 \mathrm{~nm}$ emission on the negative axis, and at 350 , $375,400 \mathrm{~nm}$ excitation and 440, 452, $459 \mathrm{~nm}$ emission, respectively, on the positive axis. 


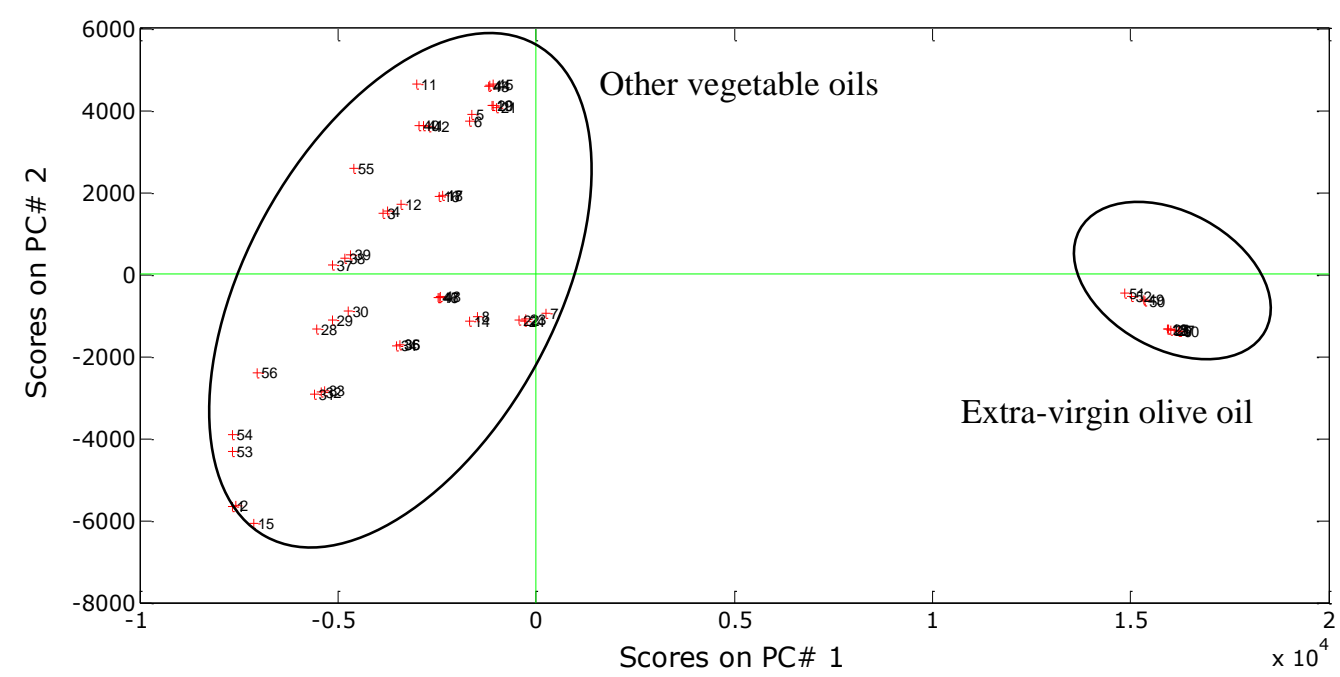

Figure 3. PC1 x PC2 scores for samples of extra virgin olive oil and other vegetable oils (corn, soybean, canola and sunflower)

\subsection{PLS of spectra of mixtures of soybean oil in extra-virgin olive oil}

Through the Partial Least Squares (PLS) multivariate calibration technique, it was possible to build a model correlating the concentration of extra-virgin olive oil with the fluorescence spectra. The PLS model had an $\mathrm{R}^{2}$ of 0.99412 and low RMSEP (3.59), RMSEC (2.32) and bias (4.77. 10-7) values. Thus, one can consider the model exact for both calibration and prediction (Figure 4).

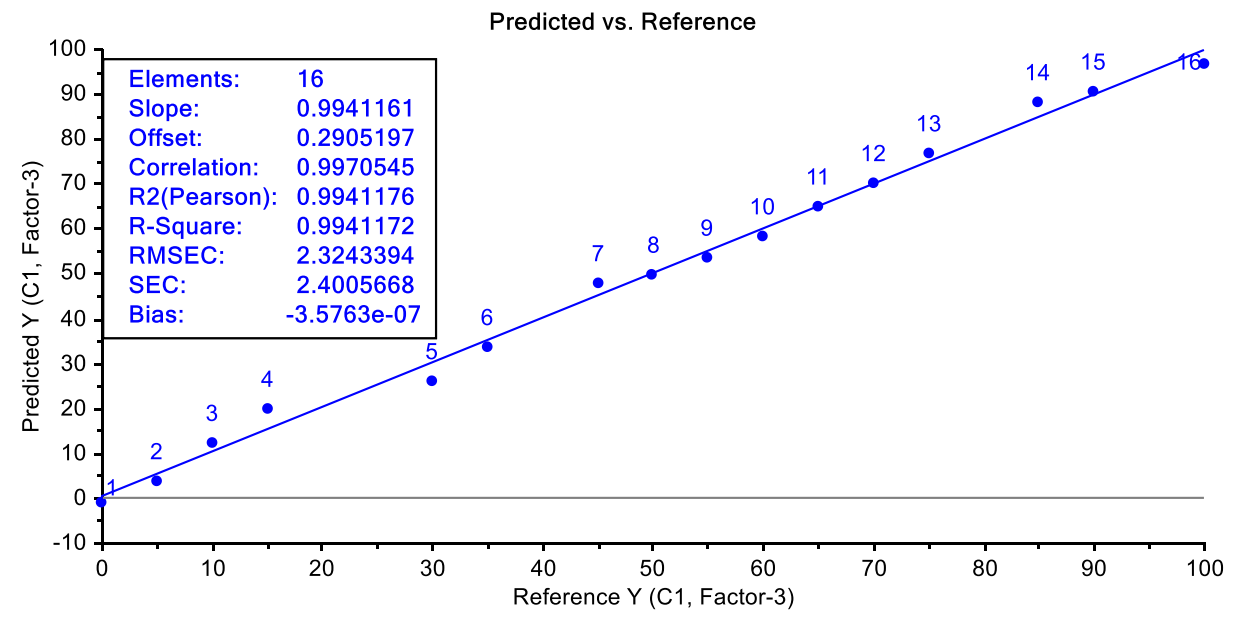

Figure 4. PLS mixtures of olive oil, extra-virgin olive oil and soybean oil in the range of 0-100\%

\section{Conclusions}

Due to lower market prices, edible oils such as soybean, corn, canola, and sunflower are likely to be used as adulterants of extra-virgin olive oil for illicit enrichment. The method proposed in this paper, which combined spectrofluorimetry with PCA and PLS, was characterized as fast and accurate in detecting tampering and has the potential to be used for quality control and labeling of the best-quality olive oils.

\section{Acknowledgments}

The authors thank Fapesb and CNPq for financial aid and scholarships.

\section{References}

Acín, S., Navarro, M.A., Carnicer, R., Arbonés-Mainar, J.M., Guzmán, M.A., Arnal, C., Beltrán, G., Uceda, M., Maeda, N., \& Osada, J. (2005). Dietary cholesterol suppresses the ability of olive oil to delay the 
development of atherosclerotic lesions in apolipoprotein E knockout mice. Atherosclerosis. 182(1), 17-28. http://dx.doi.org/10.1016/j.atherosclerosis.2005.01.050

Aguilera, C.M., Mesa, M.D., Ramirez-Tortosa, M.C., Nestares, M.T., Ros, E. Gil, A. (2004). Sunflower oil does not protect against LDL oxidation as virgin olive oil does in patients with peripheral vascular disease. Clinical Nutrition. 23(4), 673-681. http://dx.doi.org/10.1016/j.clnu.2003.11.005

ANVISA. Resolução $n^{\circ}$ 482. (1999). Regulamento técnico para fixação de identidade e qualidade de óleos e gorduras vegetais. Diário Oficial da República Federativa do Brasil.

Aparicio-Ruiz, R., Mínguez-Mosquera, M.I., \& Gandul-Rojas, B. (2011). Thermal degradation kinetics of lutein, $\beta$-carotene and $\beta$-cryptoxanthin in virgin olive oils. Journal of Food Composition, 24(6), 811-820. http://dx.doi.org/10.1016/j.jfca.2011.04.009

Baccouri, O., Guerfel, M., Baccouri, B., Cerretani, L., Bendini, A., Lercker, G., Zarrouk, M., \& Miled, D.D.B. (2008). Chemical composition and oxidative stability of Tunisian monovarietal virgin olive oils with regard to fruit ripening. Food Chemistry. 109 (4), 743-754. http://dx.doi.org/10.1016/j.foodchem.2008.01.034

Bosque-Sendra, J.M., Cuadros-Rodríguez, L., Ruiz-Samblás, C., \& De La Mata, A.P. (2012). Combining chromatography and chemometrics for the characterization and authentication of fats and oils from triacylglycerol compositional data: A review. Analytica Chimica Acta, 724, 1-11. http://dx.doi.org/10.1016/j.aca.2012.02.041

Calvano, C.D., De Ceglie, C., D'Accolti, L., \& Zambonin, C.G. (2012). MALDI-TOF mass spectrometry detection of extra-virgin olive oil adulteration with hazelnut oil by analysis of phospholipids using an ionic liquid as matrix and extraction solvent. Food Chemistry, 134(2), 1192-1198. http://dx.doi.org/10.1016/j.foodchem.2012.02.154

Coxam, V., \& Puel, C. Davicco, M.J. (2010). Olives and olive oil in the prevention of osteoporosis. In Victor R. Preedy and Ronald Watson (Eds.), Olives and olive oil in health and disease prevention, 1195-1203. Elsevier.

De La Cruz, J.P., Villalobos, M.A., Carmona, J.A., Martín-Romero, M., Smith-Agreda, J.M., \& De La Cuesta, F.S. (2000). Antithrombotic potential of olive oil administration in rabbits with elevated cholesterol. Thrombosis Research, 100(4), 305-315. http://dx.doi.org/10.1016/S0049-3848(00)00321-2

De La Cruz, J.P., Del Río, S., Arrebola, M.M., López-Villodres, J.A., Jebrouni, N., \& González-Correa, J.A. (2010). Effect of virgin olive oil plus acetylsalicylic acid on brain slices damage after hypoxia-reoxygenation in rats with type 1-like diabetes mellitus. Neuroscience Letters. 471(2,3), 89-93. http://dx.doi.org/10.1016/j.neulet.2010.01.017

Dong, W., Zhang, Y., Zhang, B., \& Wang, X. (2012). Quantitative analysis of adulteration of extra virgin olive oil using Raman spectroscopy improved by Bayesian framework least squares support vector machines. Analytical Methods, 4, 2772-2777. http://dx.doi.org/10.1039/C2AY25431J

Fabiani, R., \& Morozzi, G. (2010). Anticarcinogenic properties of olive oil phenols: Effects on proliferation, apoptosis and differentiation. In Victor R. Preedy and Ronald Watson (Eds.), Olives and olive oil in health and disease, pp. 981-988. Elsevier.

Fernández-Arroyo, S., Gómez-Martínez, A., Rocamora-Reverte, L., Quirantes-Piné, R., Segura-Carretero, A., Fernández-Gutiérrez, A., \& Ferragut, J.A. (2012). Application of nanoLC-ESI-TOF-MS for the metabolomic analysis of phenolic compounds from extra-virgin olive oil in treated colon-cancer cells. Journal of Pharmaceutical and Biomedical Analysis, 63, 128-134. http://dx.doi.org/10.1016/j.jpba.2012.01.033

Flynn, M.M., \& Mega, A. (2010). Treating Recurrent prostate cancer with a plant-based, olive oil diet. Journal of the American Dietetic Association, 110(9), Supplement, A12. http://dx.doi.org/10.1016/j.jada.2010.06.037

Fragaki, G., Spyros, A., Siragakis, G., Salivaras, E., Dais, P. (2005). Detection of extra virgin olive oil adulteration with lampante olive oil and refined olive oil using nuclear magnetic resonance spectroscopy and multivariate statistical analysis. Journal of Agricultural and Food Chemistry, 53(8), 2810-2816. http://dx.doi.org/10.1021/jf040279t

Guimet, F., Ferré, J., Boqué, R. (2005). Rapid detection of olive-pomace oil adulteration in extra virgin olive oils from the protected denomination of origin "Siurana" using excitation-emission fluorescence spectroscopy and three-way methods of analysis. Analytica Chimica Acta, 544(1, 2), 143-152. 
http://dx.doi.org/10.1016/j.aca.2005.02.013

Huang, C.L., Sumpio, B.E. (2008). Olive oil, the Mediterranean diet, and cardiovascular health. Journal of the American College, 207(3), 407-416. http://dx.doi.org/10.1016/j.jamcollsurg.2008.02.018

Kim, J., Kim, D.N., Lee, S.H., Yoo, S.H., Lee, S. (2010). Correlation of fatty acid composition of vegetable oils with rheological behaviour and oil uptake. Food Chemistry, 118(2), 398-402. http://dx.doi.org/10.1016/j.foodchem.2009.05.011

Lee, D.S., Noh, B.S., Bae, S.Y., Kim, K. (1998). Characterization of fatty acids composition in vegetable oils by gas chromatography and chemometrics. Analytica Chimica Acta, 358(2), 163-175. http://dx.doi.org/10.1016/S0003-2670(97)00574-6

Logan, A.C. (2005). Omega-3 and depression research: Hold the olive oil. Prostaglandins, Leukotrienes and Essential Fatty Acids, 72(6), 441. http://dx.doi.org/10.1016/j.plefa.2005.02.006

Menendez, J.A., Papadimitropoulou, A., Vellon, L., Lupu, R. (2006). A genomic explanation connecting "Mediterranean diet", olive oil and cancer: Oleic acid, the main monounsaturated fatty acid of olive oil, induces formation of inhibitory "PEA3 transcription factor-PEA3 DNA binding site" complexes at the Her-2/neu (erbB-2) oncogene promoter in breast, ovarian and stomach cancer cells. European Journal of Cancer, 42(15), 2425-2432. http://dx.doi.org/10.1016/j.ejca.2005.10.016

Mignani, A.G., Ciaccheri, L., Ottevaere, H., Thienpont, H., Conte, L., Marega, M. et al. (2011). Visible and near-infrared absorption spectroscopy by an integrating sphere and optical fibers for quantifying and discriminating the adulteration of extra virgin olive oil from Tuscany. Analytical and Bioanaytical Chemistry, 399(3), 1315-1324. http://dx.doi.org/10.1007/s00216-010-4408-y

OLIVA: Conhecendo melhor o azeite de oliva, 2011. URL: http://www.oliva.org.br/conhecendo-o-azeite.php. Accessed 19 07.13.

Papadopoulos, K., Triantis, T., Tzikis, C.H., Nikokavoura, A., \& Dimotikali, D. (2002). Investigations of extra virgin olive oils with seed oils using weak chemiluminescence. Analytica Chimica Acta, 464(1), 135-140. http://dx.doi.org/10.1016/S0003-2670(02)00436-1

Perona, J.S., Cañizares, J., Montero, E., Sánchez-Domínguez, J.M., Catalá, A., \& Ruiz-Gutiérrez, V. (2004). Virgin olive oil reduces blood pressure in hypertensive elderly subjects. Clinical Nutrition, 23(5), 1113-1121. http://dx.doi.org/10.1016/j.clnu.2004.02.004

Poulli, K.I., Mousdis, G.A., \& Georgiou, C.A. (2007). Rapid synchronous fluorescence method for virgin olive oil adulteration assessment, 105, 369-375. http://dx.doi.org/10.1016/j.foodchem.2006.12.021

Sikorska, E., Khmelinskii, I., \& Sikorski, M. (2012). Analysis of olive oils by fluorescence spectroscopy: Methods and applications. In Boskou Dimitrios (Ed.), Agricultural and Biological Sciences - Olive Oil Constituents, Quality, Health Properties and Bioconversions, pp.63-88. http://dx.doi.org/10.5772/30676

Van Tol, A., Terpstra, A.H.M., Van den Berg, P., \& Beynen, A.C. (1999). Dietary corn oil versus olive oil enhances HDL protein turnover and lowers HDL cholesterol levels in hamsters. Atherosclerosis, 147(1), 87-94. http://dx.doi.org/10.1016/S0021-9150(99)00167-7

Viola, P., \& Viola, M. (2009). Virgin olive oil as a fundamental nutritional component and skin protector. Clinics in Dermatology, 27(2), 159-165. http://dx.doi.org/10.1016/j.clindermatol.2008.01.008

\section{Copyrights}

Copyright for this article is retained by the author(s), with first publication rights granted to the journal.

This is an open-access article distributed under the terms and conditions of the Creative Commons Attribution license (http://creativecommons.org/licenses/by/3.0/). 